\title{
MIMR LIVED EXPERIENCES OF BADJAO FEMALE WHO ENTERED EARLY MARRIAGE: A PHENOMENOLOGICAL STUDY
}

\author{
Abdullah Junior S. Mangarun*, Llana Almira A. Agao-Agao, Duchess Raeven A. Gimena, \\ Arreane T. Tumanda \\ College of Nursing, Mindanao State Universty-lligan Institute of Technology, Philippines \\ "Corresponding Author's Email: abdullahjr.mangarun@g.msuiit.edu.ph
}

\begin{abstract}
Marriage is a social institution that unites people in a special form of mutual dependence for the purpose of founding and maintaining a family (Omobola, 2013). In the year 2016, about $2 \%$ of the Philippine's total population were already married at the age of 15 and $15 \%$ were married at the age of 18 . Many of these marriages, where one or both partners were below 18 years, took place in poor, rural areas, where norms are tolerating, if not encouraging. The practice is common. The purpose of this study is to know the lived experiences of female Badjao who entered into early marriages. Badjao is a tribal group in the Philippines, also known as the Sea Gypsies. The study made use of the phenomenological approach, particularly transcendental approach, to have a better understanding of their livedexperiences as teenage wives. Self-made open-ended questions were raised during interview using interview guide. The study was conducted in Barangay Tambacan with majority of Badjao residents in Iligan City. Respondents were purposively selected based on the following criteria: (1) Badjao women who have been married at the age of 13-18; (2) married for at least 5 years; and (3) willing to participate in this study.Using thematic analysis, three solid themes emerged: (1) early marriage is dictated by culture and tradition, (2) early marriage inspired by love and intimacy, and (3) early marriage is pushed by security for basic needs. Most participants were propelled into marriage because of culture and tradition, parental pleasure and age. They fear no one would marry them at an older age. Participants perceived marriage as two people who love each other, however, some participants expressed that they opt to marry with the thought that their partners will be able to sustain their basic needs. Most participants were contented of their lives marrying at a young age. The data suggests that Badjaos need support, services and assistance in all areas of their daily living.
\end{abstract}

\section{Keywords: Badjao, Early Marriage, Phenomenology, Philippines}

\section{INTRODUCTION}

\section{Background of the study}

Marriage is a social institution that unites people in a special form of mutual dependence for the purpose of founding and maintaining a family (Omobola, 2013). Many societies have norms that limit the age of young girls to enter into marriage, but in some cases the age limits are not taken into consideration when related to the physiological readiness for child bearing(Giday, 2006). Marriage often takes place at ages much earlier than the legally ratified minimum age. Early marriage is the marriage of children and adolescents below the age of 18 years. In several cultures, girls are forced to be married at a very early age due to various reasons such as getting dowry, the fear of some parents that their daughters would get pregnant while at home, and so on (Dhital, 2000).

In the Philippines, $2 \%$ of the total population were already married at the age of 15 and $15 \%$ were married at the age of 18.Many early marriages in rural area takes place because of poverty where one or both the partners are below 18 years (Hotchkiss, Godha \& Gage, 2013).

There are various factors contributing to the existence of early marriage including male dominance, parents' ignorance and social forces (Ahmed et al., 2014). According to Loaiza \& Wong (2012), early marriage is most likely to occur among girls who are poor, have low education level, and live in rural areas. It denies girls opportunities to be educated and build life skills, separates them from family and friends, compromises their ability to assume health promotion practices and seek timely care, and enhances their vulnerability to considerable health and social problems (Chanra-Mouli et al., 2013; Dickens, 2015; Sabbe et al., 2013; Santhya, 2011).

Early marriage put teenagers at risk because they are not fully physically developed to care for pregnancy. Early marriage results in early and frequent child birth 
and subsequently an increase in family size (Michael, 2014). High rates of unintended pregnancy, abortion, preterm labor, delivery of low birth weight babies, and fetal and maternal mortality are observed among teenage girls and are strongly correlated with early marriage. Moreover, the girls who are married as teenagers are also affected psychologically and they are more likely to experience depression, anxiety, and other mood disorders (Ahmed et al., 2014).

Early marriage is common all over the globe. Poor health, early death and lack of educational opportunities lead the list of its factors. Proper health interventions for managing early marriage need to apply the communitybased approach. However, it has received less attention from policymakers and health researchers in the Philippines. Therefore, this phenomenological study sought answers to the question; "What are the lived experiences of female Badjao who entered into early marriage?"The goal is to develop and implement effective and comprehensive programs aimed at raising awareness among families and communities regarding theconsequences of early marriage.

\section{Badjao}

Widely known as the "Sea Gypsies" of the Sulu and Celebes Seas, the Badjao are scattered along the coastal areas of Tawi-Tawi, Sulu, Basilan, and some coastal municipalities of Zamboanga del Sur in the ARMM. Amongst themselves, they're known as SamaLaus (Sea Sama) and are found living on houseboats where they make their livelihood solely on the sea as expert fishermen, deep sea divers, and navigators. They move with the wind and the tide, on their small houseboats called vintas. They come to shore to barter their harvests for farmed produce such as fruits and cassava, as well as, replenish their supplies and/or make repairs to their houseboats (Peralta, 2002).

At present the Badjao are the most marginalized ethnic group and one of the poorest tribes in the Philippines, a Muslim tribe that is shunned by almost everyone, still gypsies, but also named tramps and thieves. Their vibrant nomadic lifestyle, the way of life bequeathed to them by their ancestors has vanished in most parts of Mindanao (De Jong, 2010).

\section{RESEARCH METHODOLOGY}

The study made use of phenomenological approach, particularly transcendental approach, to have a better understanding of their lived-experiences as teenage wife. Participants were purposively selected based on the following criteria: (1) Badjao women who have been married at the age of 13-18; (2) married for at least 5 years; and (3) willing to participate in this study. The study was conducted in the community of the Badjao along the coastal areas of Tambacan, Iligan City.A free prior-informed consent of the barangay captain and the leader of the Badjao were secured by the researchers to be used as a tool for gaining entry.

The main instrument for data collection is interview. Interviews were conducted by a single researcher together with an interpreter to aid in a healthy interaction and conversation. The data were driven from semi-structured, in depth, and face-to-face interviews with selected participants. Sampling continued until saturation of data was reached. All participants were interviewed at their respective houses privately and they were asked to talk about the conditions that propelled them to early marriage. The general question for the interview is as follows: "Could you tell me about your marriage?" Probing questions were also used to clarify participants' descriptions, such as "When you said... what did you mean? Could you explain more about that?" Duration of the interview sessions varies from 10 to 15 minutes. All interviews were audio recorded in MP3 format and transcribed verbatim from Badjao dialect to English language (Montazeri et al., 2016).A total of 4 participants have been interviewed and saturated the data needed for the study. All participants were informed that thier participation was voluntary and they can stop anytime even during the interview and the confidentiality will be strictly preserved.

This study employed the phenomenological approach to analyze the data. All interviews were read for several times to gain a sense of the whole. The transcripts were then divided into categorized participants' individual interpretation of the interview questions and how they answered which were then abstracted and coded. Then, codes were compared according to similarities and differences and sorted into categories and subcategories constituting the manifest content. The tentative categories were revised by the research team members. Finally, categories are formulated as the latent content of the text. In addition, all transcripts are translated from Badjao dialect to English language by the authors with 
the help of an interpreter (Montazeri et al., 2016).

\section{RESULTS}

This phenomenological study presents the lived experiences of female Badjao who entered into early marriage. According to Bogdan \& Biklen (1993), phenomenology provides an opportunity for individuals to share their life experiences in order to illuminate the previously misunderstood, unknown, or discounted. A mixture of experiences is provided to help the reader understand the research participants. To provide various outlooks, quotations allow the participants to speak for themselves. The participants are coded to hide their real identity. Participant 1 is coded as p: 1 , participant 2 is coded as $\mathrm{p}: 2$, participant 3 is coded as p:3, and participant 4 is coded as p:4 (Table).

\section{Table: Participants of the Study}

\begin{tabular}{|c|c|c|c|}
\hline Participants Code & Age & Age During Marriage & Years Married \\
\hline Participant 1: p:1 & 32 & 15 & 17 \\
\hline Participant 2: p:2 & 23 & 15 & 8 \\
\hline Participant 3: p:3 & 28 & 13 & 15 \\
\hline Participant 4: p:4 & 57 & 15 & 42 \\
\hline
\end{tabular}

Table presents the demographic profile of the participants which includes the present age, estimated age during marriage and the duration of marriage in years. The participants are coded as shown in the table, for example, participant 1 is coded as p: 1, participant 2 is coded as p:2, and so on.Of the series of interviews conducted, several themes emerged. The researchers were able to classify threads woven during the course of the interviews. After a long discussion, three themes remained: (1) early marriage in Badjao community is dictated by culture and tradition, (2) early marriage is inspired by love and intimacy, and (3) early marriage is pushed by security for basic needs.

The Phenomena of Early Marriage among Badjao Early marriage is dictated by culture and tradition. Culture and tradition is one of the factors that propelled the participants to marry. The findings showed that Badjao get married as early as 13 to 18 years old following their tradition. They fear that no one would like to marry them at an older age. This is the fundamental reason that influenced them to get married. It is in their culture that once they are in the adolescence stage, parents arranged their marriage. Most participants mentioned that parental pleasure is objectively obtained when the parents of both sides made an agreement to get their child married only with the approval of the girl and boy. The participants stated:

"Yes, we'll be happy when a couple wants to get married. Almost all of them are aged 15, 16 and 17. No. Because that is already our rule; if you won't marry at a young age you'll feel shy when you get old. In marriage, for example, if a mom has a son then your mom and my mom will agree whether or not they will allow their children to marry each other. And when they are going to ask their child if they are really willing to marry each other and they really wanted to then that's when marriage happens." p:1

15

"It is ordinary for us to get married at an early age, as it would be embarrassing if we grow older yet remained single. In my case, I am already allowed to marry because I was fifteen at that time, however, it was due to my mom's situation which pushed me to marry back then. And, as long as the parents of both the boy and girl made an agreement for them to get married with their [the girl and the boy] consent, then marriage will take place thereafter. That's our culture. "p:2

"Marriage for us is when parents from both sides planned and talked about this. I am not forced to enter into marriage at an early age. It's okay for us to get married at an early age because that is our tradition here." $\mathbf{p : 3}$

"When the mothers agree and then after seeking the approval of the girl and the boy, then the ceremony of marriage will proceed. We don't see any problem on it. This is really the rule in our Badjao community. It doesn't matter if you marry at a young age because it is part of our rules." p:4

Early marriage is inspired by love and intimacy. Participants believed that love is one of the reasons when couples decided to finally get married and has made up their 
minds already on building their own family ahead of marriage. Most participants were contented of their lives marrying at the young age. The needs of the family were sustained by the husbands who went fishing while the women were taking care of the household chores and the children. Marriage is not difficult for them.

"We fell in love with each other...we met here and fell in love. I felt happy because my husband is supporting me." p:1

"If two people marry for the reason that they love each other, we feel happy for them because by then they will be starting a family of their own." $\mathbf{p : 2}$

Another participant added, "There was no fight between us, and then we have a stable married life. "p:4

Early marriage is pushed by security for basic needs. Socioeconomic difficulties were one of the fundamental reasons that persuaded the particpants to get married. According to them, in a marriage and in a family, the husband's traditional role is to provide for the family, earning money by working a job. From the participants' perspectives, the husband is the breadwinner and the wife is the one who takes care of the children and does the household chores.

According to one of the participant, her family has no stable income to sustain their needs which resulted to the marriage.

"The fact that no one will support my daily needs if I will not marry; thus, the husband will work outside of the house, peddling or fishing while I am sewing. "p:4

Another participant added that her mother's health concern was another factor that pushed her to marry.

"When my mother gave birth through a Cesarean operation, I was forced to marry so we can use my dowry to pay for the hospital fees. My husband is in charge of looking for livelihood activities where he can earn because he is the foundation of the household, while I, as a wife, am just supporting him. "p:2

The participants believed that they could achieve their basic needs through marriage with the help of their husband. One of them stated,

"I don't think that our lives were difficult after getting married because my husband is a fisherman and we can eat with the use of the money he got from fishing. Whenever we got into a fight, we would only talk about it, no violence at all. The husband needs to work to support his families'financial needs. As a wife, I will be the one taking care of our children and do the household chores like cooking and washing the dishes. "p:3

\section{DISCUSSION}

The current study aimed to explore the lived experiences of female Badjao who entered early marriages. The study revealed that the participants perceived marriage as an usual and cultural event even though they were unprepared to accept the roles and responsibilities of husband and wife. The reasons behind early marriage vary from one country to another. Most studies have shown that the dominant reason is culture. According to the results, culture was one of the factors that propelled the girls to early marriage. Badjao tradition of marriages is prearranged by the parents for their sons and daughters at an early age; the process is similar to other ethnic groups, in which a dowry is often presented to the parents of the woman that a man wishes to marry (Peralta, 2002). Consequently, early marriage has remained common and it is still encouraged by Badjao culture. To sum up the results, all of the four participants stated that they get married because it is influenced by their cultural practice. As soon as they reach the adolescence stage as early as 13 years old, and are capable to conceive a child, they are considered a candidate for marriage. The ceremony only takes place once the parents of both sides agree for the marriage with the approval of the girl and the boy, and then a dowry will be offered by the family of the groom to the family of the bride. As part of the ceremony, a feast will be arranged to welcome the newly wedded couple alongside songs and dances. In addition, the participants further stated that it is their standard, as integrated in their custom and tradition, to marry early since it will become an embarrassment as they age yet remain single.

Love is the foundation of marriage. One of the other factors that propelled the participants to accept early marriage was a response to their emotional needs. According to one of the participants, love is one of the reasons why they decided to get married. They met in Tambacan, Iligan City, where they fell in love with 
each other and persuaded to marriage. However, according to participants, love is just an outcome of marriage. Over time, they have learned to love their husbands because of the respect, peace and love they received from their partners. Similarly, in Ben-Zeev's study entitled "Is Love Really Essential to Marriage?" Ben-ze'ev \& Goussinsky, 2008, love has been seen as a desirable outcome of marriage in many cultures, but not as a good reason for getting married in the first place. Moreover, the participants expressed that they are contented of their lives marrying at such a young age. True to what they said, they were not prepared to accept the roles of being a wife. However, due to their supporting environment, with the help of their parents, they were able to learn how to care for their child, perform houseld chores and look for livelihood activities. Through that, they were able to manage as they establish a family of their own, thus, strengthening the relationship of the young couple. Additionally, it was mentioned that throughout their married life, no violence was enacted by one of the couple to the other. Once crisis arise, verbal arguments are made without physical harm done. As a result, marriage is not difficult for them.

Child marriage is most common in the world's poorest countries and is often concentrated among the poorest households within those countries. It is closely linked with poverty and low levels of economic development. Financial crisis is one of the reasons why people marry at an early age. Arranging for their daughters to be married early can relieve immediate financial pressures for families living in extreme poverty (Robinson, 2014). In the current study, one of the participants opts to marry because she wanted to escape from the financial difficulties that her family was going through. Another participant said that she was forced to marry so that the dowry that will be given to her will be used to pay up for her mother's hospital fees. Also, the participants believed that they could meet their basic needs with the help of their spouse. Similarly, according to Challies (2009), the husband is to lead in the area of finances. In most cases this means that the husband will be the family's breadwinner, freeing up their wife to pursue her vocation in the home as wife and mother.

\section{CONCLUSION}

It is concluded from the study that Badjao women have not experienced violence from their partners throughout their married life. Their tradition influenced them to marry early and not because of their sexual desires. On the other hand, one participant was engaged to marry early due to circumstantial factor in line with scarcity of resources. In addition, due to lack of knowledge and maturity there are maternal complications present during their pregnancy and even child mortality is noted.

Badjaos are culturally bound though they belong to a different community. Based on the results, three of the participants married early because it is their cultural practice. It is therefore concluded that Badjaos were not influenced by the practices of people in the society they belong. Tambacan as part of Iligan City is an urban area but amidst cultural diversity, Badjaos were not stirred to be socialized the way people lived.On the contrary, education has changed one Badjao female's perception of marriage. She perceived that marrying early is difficult especially when it is forced due to a certain circumstance. She's the only participant who was able to study and finish elementary education. Moreover, she stated that she wanted to encourage her children to finish their study before getting married for a better future. The study has concluded that if Badjaos are open for influences especially to be educated, Badjao women would not marry early and aspire for better living conditions.

\section{ACKNOWLEDGEMENT}

The researchers would like to acknowledge Pastor Ronnie, tribal leader, for helping us identify the participants and for serving as our interpreter.

\section{REFERENCES}

Ahmed, S., Khan, A., Khan, S. \& Noushad, S. (2014). Early marriage; A Root of Current Physiological and Psychosocial Health Burdens. International Journal of Endorsing Health Science Research, 2 (1), pp 50-53.

Ben-Ze'ev, A. \& Goussinsky, R. (2008). In the Name of Love: Romantic Ideology and Its Victims. $1^{\text {st }}$ edition, Oxford University Press, India. 
Bogdan, R. C. \& Biklen, S. K. (2003). Qualitative Research of Education: An Introductive to Theories and Methods ( $4^{\text {th }}$ edition), Allyn and Bacon, Boston.

Challies, T. (2009). Leadership in the Home - A Godly Man Provides. Retrieved from: https://www.challies .com/christian-living/leadership-in-the-home-agodly-man-protects/.

Chanra-Mouli, V., Greifinger, A., Nwosu, A., Hainsworth, G., Sundaram, L., Hadi, S., McConville, F., Benevides, R., Simon, C., Patkar, A., Schoening, E., Sethi, D., Boldosser-Boesch, A., Awasthi, P., Mathur, A. \& Braeken, D. (2013). Invest in Reproductive health, 10 (51). Pages 5.

De Jong, R. (2010). The Last Tribes of Mindanao, Badjao, the Sea Gypsies. Things Asian. Retrieved from: http://thingsasian.com/story/last-tribesmindanaobad-badjao-sea-gypsies.

Dhital, R. (2000).Child Marriage in Nepal. Retrieved from: http:/www.cwin.org.np/resources/issues/childmarriage.htm.

Dickens,B.(2015). Ethical Considerations on the Health Consequences of Child or Adolescent Marriage. Obstretrics \& Gynaecology, 128(1), pp 83-84.

Giday, T. (2006). Causes and Consequences of Early Marriage in the Amhara Region of Ethiopia. Ababa Addis, Pathfinder International, Ethiopia. Retrieved From: https: //www.pathfinder.org/wp-content/uploads /2008/01/Causes-and-Consequences-of-Early-Marriage -in-the-Amhara-Region-of-Ethiopia.pdf .

Hotchkiss, D.R., Godha, D. \& Gage. (2013).Association Between Child Marriage and Reproductive Health Outcomes and Service Utilization: A Multi-Country Study from South Asia. Journal of Adolescent Health, 52(5), pp 552-558.

Loaiza, E. S. \& Wong, S. (2012). Marrying too Young.
End Child Marriage. United Nations Population Fund, New York.

Michael, R. (2014). Factors Which Contribute to Early Marriage among Teenagers in Rural Areas: A Case Study Casulu District in Kigoma Region. Retrieved From:http://repository.out.ac.tz//584/1/DISSERTA TI-ON-RUTH.pdf.

Montazeri, S., Gharacheh, M., Mohammadi, N., Rad, J. \& Ardabili, H. (2016). Determinants of Early Marriage from Married Girls' Perspectives in Iranian Setting: A Qualitative Study. Journal of Environmental and Public Health, pp 1-8.

Omobola, O. C. (2013). Influence of Socio-Economic Change on Marriage Norms in the Yoruba Soiety, in Southwest Nigeria. Academic Journal of Interdiscip -linary Studies, 2 (3), pp 139-146.

Peralta, J.T. (2002). Glimpses: Peoples of the Philippines.National Commision for Culture and the Arts. Retrieved From: http://ncca.gov.ph/aboutculture-and-arts/culture-profile/e-books/glimpses-peoples-philippines-e-book/.

Robinson, L. (2014). Early marriage and poverty: Why we must break the cycle. Retrieved From: https://wwwone.org/us/2014/07/08/early-marriage -and-poverty-why-we-must-break-the-cycle/.

Sabbe, A., Oulami, H., Zekraoui, W., Hikmat, H., Temmerman, M. \& Leye, E. (2013). Determinants of Child and Forced Marriage in Morocco: Stakeholder Perspectives on Health, Policies and Human Rights. BMC International Health and Human Rights, 13(1).pp 1-12.

Santhya, K. G. (2011). Early Marriage and Sexual and Reproductive Health Vulnerabilities of Young Women: A Synthesis of Recent Evidence from Developing Countries. Current Opinion in Obstetrics and Gynaecology, 23(5), pp 334-339. 